\title{
Obesity and Polypharmacy among African American Older Adults: Gender as the Moderator and Multimorbidity as the Mediator
}

\author{
Shervin Assari ${ }^{1, *(\mathbb{D})}$, Cheryl Wisseh ${ }^{2}$ and Mohsen Bazargan ${ }^{1,3}$ \\ 1 Department of Family Medicine, Charles R Drew University of Medicine and Science, \\ Los Angeles, CA 90095, USA; mobazarg@cdrewu.edu \\ 2 Department of Pharmacy Practice, West Coast University School of Pharmacy, \\ Los Angeles, CA 91606, USA; cWisseh@westcoastuniversity.edu \\ 3 Department of Family Medicine, University of California Los Angeles (UCLA), Los Angeles, CA 90095, USA \\ * Correspondence: assari@umich.edu; Tel.: +1-734-858-8333
}

Received: 23 May 2019; Accepted: 6 June 2019; Published: 20 June 2019

\begin{abstract}
Despite high prevalence of obesity and polypharmacy among African American (AA) older adults, little information exists on the associations between the two in this population. This study explored the association between obesity and polypharmacy among AA older adults who were residing in poor urban areas of South Los Angeles. We also investigated role of gender as the moderator and multimorbidity as the mediator of this association. In a community-based study in South Los Angeles, 308 AA older adults (age $\geq 55$ years) were entered into this study. From this number, 112 (36.4\%) were AA men and 196 (63.6\%) were AA women. Polypharmacy (taking 5+ medications) was the dependent variable, obesity was the independent variable, gender was the moderator, and multimorbidity (number of chronic medical conditions) was the mediator. Age, educational attainment, financial difficulty (difficulty paying bills, etc.), income, marital status, self-rated health (SRH), and depression were the covariates. Logistic regressions were used for data analyses. In the absence of multimorbidity in the model, obesity was associated with higher odds of polypharmacy in the pooled sample. This association was not significant when we controlled for multimorbidity, suggesting that multimorbidity mediates the obesity-polypharmacy link. We found significant association between obesity and polypharmacy in AA women not AA men, suggesting that gender moderates such association. AA older women with obesity are at a higher risk of polypharmacy, an association which is mainly due to multimorbidity. There is a need for screening for inappropriate polypharmacy in AA older women with obesity and associated multimorbidity.
\end{abstract}

Keywords: African American; Black; elderly; older adults; medication use; polypharmacy; body mass index; obesity

\section{Introduction}

Polypharmacy (taking $5+$ medications a day) [1,2] increases the risks of adverse drug events (ADEs), drug-drug interactions, and medication nonadherence [3,4]. Polypharmacy also increases the risk of various undesired but preventable health outcomes [5-8], including, but not limited to, cognitive decline, falls, emergency department visits, unnecessary hospitalization, and mortality $[3,4,9,10]$. Polypharmacy also adds to the risk of inappropriate use of medications (IUM) [11,12]. Such negative health outcomes impose a risk on the patient and an economic burden to the health care system [11].

There is a need to study the association between obesity and polypharmacy in African American (AA) older adults for multiple reasons. First, there is a growing epidemic of polypharmacy in the US as the population is aging [11-14]. Given that advanced age is the largest contributing factor to 
the prevalence of polypharmacy, we should know more about the correlates of polypharmacy in AA older adults who have multiple chronic diseases and multimorbidity. While it has been demonstrated that polypharmacy is closely associated with major health problems [9,10], little is known on how obesity may contribute to the risk of polypharmacy of AA older adults. Inappropriate polypharmacy is dangerous for older adults who experience vulnerability due to age-related physiological changes and frailty [15]. Some reports suggest that half of older adults take at least one medication that is unnecessary [11], which increases their risk of ADEs and drug-drug interactions as well as health care costs $[11,16,17]$. Inappropriate polypharmacy is also responsible for up to $12 \%$ of all largely preventable hospitalizations of elderly individuals [18-20].

When compared to obesity, more is known regarding the associations of polypharmacy with other health problems such as multimorbidity, chronic diseases (CDs) [21], self-rated health (SRH), depression [22-24], and distress [25]. From the existing literature, few studies have enrolled AA adults [2], and even fewer have specifically focused on AA older adults [25]. As race alters correlates of several health constructs [26], including, but not limited to, obesity [27-31], additional studies are required that explore the association between polypharmacy and obesity in AA older adults. Such studies may generate results that can potentially help with health promotion programs and resources targeting the reduction of inappropriate polypharmacy in AA older adults.

There is a paucity of data on whether obesity correlates with polypharmacy among AA older adults $[2,25,32,33]$. Furthermore, although some recent studies have explored correlates of polypharmacy in this population [34-37], very limited knowledge is available on how elimination of disparities in obesity would contribute to the elimination of disparities in the polypharmacy in AA older adults in US.

Several potential factors increase vulnerability of AA older adults to polypharmacy. Low socioeconomic status, financial difficulties, low health literacy, multiple competing health needs, and poor access to healthcare (\% uninsured and underinsured) are all crucial components of the recipe to polypharmacy and its associated burden [15]. In comparison to their White counterparts, AA older adults have a lower likelihood of receiving the most effective, and the most up to date medication regimens for their health conditions $[38,39]$. Lower quality of care combined with a wide range of biases against AA older adults who attend the healthcare system increases their risk of being prescribed multiple medication regimens [2,25]. As a result, racial disparities may exist in the risk of inappropriate medication use and polypharmacy among older adults [38,39].

Gender is a central risk factor that shapes prevalence of polypharmacy [40,41]. There are multiple studies showing that women may have a higher risk of polypharmacy than men [40-43]. In another study of AA older adults, gender, in addition to multimorbidity, potentially inappropriate medication use, and number of healthcare providers, predicted polypharmacy [25]. As gender alters determinants and consequences of various health outcomes [40,42] including but not limited to polypharmacy [44-47], additional studies should explore the link between obesity and polypharmacy in AA older adults as well as other factors such chronic disease burden and gender.

Aims

The purpose of the current study was to investigate the associations between obesity and polypharmacy (taking $5+$ medications) among AA older adults. We also tested whether gender moderates and whether multimorbidity (number of $\mathrm{CDs}$ ) mediates this association.

\section{Materials and Methods}

\subsection{Design and Setting}

The current cross-sectional study used a survey and a comprehensive evaluation of medications taken. The study was conducted in south Los Angeles, California, USA. Data were gathered between 2015 and $2018[48,49]$. 


\subsection{Ethics}

The study protocol received ethical approval by the Charles R. Drew University of Medicine and Science (CDU) Institutional Review Board (IRB), Los Angeles, California, USA (CDU IRB\#: 14-12-2450-05). All participants provided a written informed consent before they were enrolled to the study. Participants were financially compensated.

\subsection{Process and Data Collection}

The data collection was composed of two main components: (1) a structured face-to-face interview and (2) a comprehensive investigation of medications taken. During the structured interviews, a wide range of data were collected that included (1) demographic factors (gender and age), (2) SES (educational attainment, financial difficulty, income, marital status, or living alone), and (3) health including but not limited to multimorbidity (number of CDs), SRH, depression, and obesity.

\subsection{Participants}

Our study enrolled a nonrandom sample of AA older adults from economically disadvantaged areas in South Los Angeles (e.g., Watts area). Using convenience sampling, participants were eligible for enrollment if they were (1) African American/AA, (2) were 55 years or older, and (3) could complete an interview in English. Participants were excluded if they were (1) institutionalized or (2) enrolled in other clinical trials.

Participants in our study were sampled from 11 senior housing apartment units, 16 AA churches, and several low-income public housing projects, all located in Service Planning Area 6 (SPA 6), Los Angeles County, California. The LA Department of Public Health divided LA County into eight SPAs to better conduct surveillance and to better provide public health services to LA county residents, considering their specific needs. In SPA 6, $49 \%$ of older adults are AAs, $58 \%$ of adults have an income level less than $200 \%$ of the federal poverty line (FPL), and 36\% are uninsured. Between 2013 and 2015, homeless AA individuals in SPA6 increased from 39\% to 70\% [48,49].

\subsection{Analytical Sample}

The current analysis included 308 AA older adults (age $\geq 55$ years) which comprised of 112 (36.4\%) AA men and 196 (63.6\%) AA women.

\subsection{Measurements}

Obesity: This study measured BMI based on measured weight and height. Height was measured in feet/inches. Body weight was measured in pounds. To calculate BMI, first, height, and weight were converted to meters and kilograms, respectively. We calculated BMI by dividing body weight (kilograms) by height (meters squared). Obesity was defined as body mass index (BMI) equal to or more than 30 .

Polypharmacy: In this study, polypharmacy was measured based on a comprehensive evaluation of all medications of the individual. Polypharmacy was defined as use of $5+$ medications in a single day [1].

Sociodemographic covariates: Age, SES (educational attainment, financial difficulty, income, marital status, and living alone) were the sociodemographic variables. Age and educational attainment (years of schooling) were continuous variables. Income was monthly income in US dollars and financial difficulties were measured using three items that were based on Pearlin's list of main chronic financial difficulties experienced by low income individuals [50,51]. The three items were the frequency by which a participant did not have enough money to afford (1) clothing, (2) food, and (3) paying bills. Responses ranged from 1 (never) to 5 (always). We calculated a sum score (a higher score reflecting more financial difficulties). (Cronbach's alpha $=0.92$ ). 
Depression: This study used the 15-item short Geriatric Depression Scale (GDS) to evaluate depression [26]. Responses were on a "yes" or "no" scale. A summary score was calculated with a potential range between 0 and 15. A higher score indicated more depression. The GDS-short form has excellent reliability and validity and has been extensively used to measure depression among older adults in both clinical and community settings [49-53].

Self-Rated Health: We asked participants about their overall health. The responses ranged from excellent (1) to poor (5) [54]. We treated SRH as a continuous variable with a range from 1 to 5, where a higher score reflects poorer health. Poor SRH in turn, predicts all-cause mortality in the general population [55,56] as well as patients with chronic disease [56]. Review articles and multiple original studies have established high predictive validity of poor SRH as a robust determinant of mortality risk, above and beyond covariates such as SES and health [56-58].

Mediator: Participants' multimorbidity was operationalized as the number of CDs a participant had. Participants were asked about the presence of the following eleven CDs: hypertension, heart disease, diabetes, lipid disorder/hypercholesterolemia, cancer, asthma, osteoarthritis, thyroid disorder, chronic obstructive pulmonary disease, rheumatoid arthritis, or gastrointestinal disease. Participants reported if a physician had ever told them that they have any of the CDs previously listed. Multimorbidity was operationalized as a sum score that reflected number of CDs that were present. Self-reported CDs have high validity [59-61].

Moderator: Gender was treated as a dichotomous variable ( 1 woman, 0 men).

\subsection{Data Analysis}

For data analysis, we used SPSS 23.0 (IBM, Armonk, New York, NY, USA). We reported mean, standard deviation (SD), frequency $(n)$, and relative frequency (\%) to describe our participants both in the pooled sample and each gender. We used Chi-square and independent samples $t$-test for bivariate analyses. For multivariable analysis, logistic regression models were used. In our logistic models, polypharmacy was the main dependent variable, obesity was the main independent variable, and demographic factors (age) and SES (educational attainment, financial difficulty, income, marital status, and living alone), and SRH and depression were the covariates. Gender was the moderator and multimorbidity (number of CDs) was the mediator. Model 1 and Model 2 were conducted in the pooled sample. Model 3 to Model 4 were conducted in each gender. Models were different in regards of controlling or not controlling for multimorbidity. Mediation and moderation were defined based on Baron and Kenny [29]. We defined a third variable as a moderator if it changed the association between two variables. We defined a 3rd variable a mediator if it was associated with both of our variables and its inclusion as a control variable fully explained our primary association of interest [29]. We ran models in the pooled sample by gender and results were reported as odds ratios $(\mathrm{OR})$, standard errors (SE), and $p$-values.

\section{Results}

\subsection{Descriptive Statistics}

Table 1 describes the pooled sample based on gender. The sample included 308 AA older adults (age $\geq 55$ years). From this number, 112 were AA men (36.4\%) and 196 were AA women (63.6\%). Overall, approximately $44.8 \%$ and $68.5 \%$ had obesity and polypharmacy, respectively. 
Table 1. Descriptive characteristics in the pooled sample and by gender.

\begin{tabular}{|c|c|c|c|c|c|c|}
\hline \multirow{2}{*}{ Characteristics } & \multirow{2}{*}{\multicolumn{2}{|c|}{$\begin{array}{c}\text { All } \\
n(\%)\end{array}$}} & \multirow{2}{*}{\multicolumn{2}{|c|}{$\begin{array}{l}\text { Men } \\
n(\%)\end{array}$}} & \multirow{2}{*}{\multicolumn{2}{|c|}{$\begin{array}{c}\text { Women } \\
n(\%)\end{array}$}} \\
\hline & & & & & & \\
\hline Men & 112 & 36.4 & 112 & 100.0 & - & - \\
\hline Women & 196 & 63.6 & - & - & 196 & 100.0 \\
\hline \multicolumn{7}{|l|}{ Living Alone } \\
\hline No & 282 & 91.6 & 98 & 87.5 & 184 & 93.9 \\
\hline Yes & 26 & 8.4 & 14 & 12.5 & 12 & 6.1 \\
\hline \multicolumn{7}{|l|}{ Marital Status (Married) * } \\
\hline No & 86 & 27.9 & 38 & 33.9 & 48 & 24.5 \\
\hline Yes & 222 & 72.1 & 74 & 66.1 & 148 & 75.5 \\
\hline \multicolumn{7}{|l|}{ Poor SRH * } \\
\hline No & 176 & 57.3 & 38 & 33.9 & 48 & 24.5 \\
\hline Yes & 131 & 42.7 & 74 & 66.1 & 148 & 75.5 \\
\hline \multicolumn{7}{|l|}{ Obese * } \\
\hline No & 170 & 55.2 & 79 & 70.5 & 91 & 46.4 \\
\hline Yes & 138 & 44.8 & 33 & 29.5 & 105 & 53.6 \\
\hline \multicolumn{7}{|l|}{ Polypharmacy * } \\
\hline No & 97 & 31.5 & 42 & 37.5 & 55 & 28.1 \\
\hline Yes & 211 & 68.5 & 70 & 62.5 & 141 & 71.9 \\
\hline Age (Years) * & 69.74 & 9.18 & 68.30 & 8.46 & 70.57 & 9.49 \\
\hline Educational Attainment & 12.72 & 2.12 & 12.43 & 2.36 & 12.88 & 1.95 \\
\hline Financial Difficulty * & 11.82 & 6.04 & 13.15 & 6.61 & 11.06 & 5.55 \\
\hline Income & 2.69 & 1.11 & 2.84 & 1.32 & 2.61 & 0.97 \\
\hline Depression & 3.26 & 3.03 & 3.42 & 2.82 & 3.17 & 3.15 \\
\hline Multimorbidity (Number of CDs) * & 4.32 & 1.84 & 3.91 & 1.83 & 4.55 & 1.81 \\
\hline
\end{tabular}

CDs: Chronic Diseases; SRH: Self-Rated Health. ${ }^{*} p<0.05$. (Chi-square or independent $t$-test).

Table 1 also compares older AA men and older AA women for the study variables. Older AA men were significantly younger than older AA women. Older AA women reported more financial difficulties than older AA men. Older AA women also reported higher multimorbidity (number of CDs) compared to older AA men. Polypharmacy, obesity, and poor SRH were also more common in older AA women than older AA men (Table 1).

\subsection{Bivariate Correlations}

Table 2 shows three correlation matrices: one in the pooled sample, one in older AA men, and one in older AA women. There was a positive correlation between multimorbidity (number of CDs) and polypharmacy in the pooled sample, older AA women, and older AA men. There was also a positive correlation between obesity and polypharmacy in the pooled sample and in older AA women but not older AA men (Table 2). 
Table 2. Bivariate associations between study variables overall and by gender.

\begin{tabular}{|c|c|c|c|c|c|c|c|c|c|c|c|c|}
\hline & 1 & 2 & 3 & 4 & 5 & 6 & 7 & 8 & 9 & 10 & 11 & 12 \\
\hline \multicolumn{13}{|l|}{ All } \\
\hline 1 Gender (Women) & 1 & $0.119 *$ & 0.103 & $-0.167^{* *}$ & -0.100 & -0.110 & 0.101 & -0.044 & -0.040 & $0.233^{* *}$ & 0.098 & $0.169^{* *}$ \\
\hline 2 Age (Years) & & 1 & $-0.171^{* *}$ & $-0.272 * *$ & 0.029 & -0.092 & $0.192 * *$ & $-0.155^{* *}$ & $-0.207^{* *}$ & -0.086 & $0.158 * *$ & 0.070 \\
\hline 3 Educational Attainment & & & 1 & $-0.122 *$ & $0.215^{* *}$ & 0.074 & -0.097 & -0.121 * & $-0.162 * *$ & -0.022 & -0.068 & -0.090 \\
\hline 4 Financial Difficulty & & & & 1 & $-0.154^{* *}$ & 0.044 & -0.024 & $0.206^{* *}$ & $0.443^{* *}$ & 0.037 & -0.102 & 0.141 * \\
\hline 5 Monthly Income & & & & & 1 & $0.244^{* *}$ & $-0.214^{* *}$ & -0.071 & $-0.127 *$ & 0.090 & -0.101 & $-0.164^{* *}$ \\
\hline 6 Marital Status (Married) & & & & & & 1 & $-0.384^{* *}$ & -0.026 & 0.055 & 0.032 & 0.030 & 0.062 \\
\hline 7 Living Alone & & & & & & & 1 & -0.019 & -0.023 & 0.022 & $0.201^{* *}$ & 0.128 \\
\hline 8 SRH (Poor) & & & & & & & & 1 & 0.383 ** & 0.087 & 0.062 & $0.198^{* *}$ \\
\hline 9 Depression & & & & & & & & & 1 & 0.089 & 0.049 & $0.242 * *$ \\
\hline 10 Obesity & & & & & & & & & & 1 & $0.119 *$ & $0.147^{* *}$ \\
\hline 11 Polypharmacy & & & & & & & & & & & 1 & $0.374^{* *}$ \\
\hline 12 Multimorbidity (Number of CDs) & & & & & & & & & & & & 1 \\
\hline \multicolumn{13}{|l|}{ Men } \\
\hline 1 Gender (Women) & - & - & - & - & - & - & - & - & - & - & - & - \\
\hline 2 Age (Years) & & 1 & $-0.333^{* *}$ & $-0.279 * *$ & 0.051 & -0.177 & 0.207 * & -0.180 & -0.080 & -0.149 & 0.030 & 0.059 \\
\hline 3 Educational Attainment & & & 1 & $-0.214 *$ & $0.267^{* *}$ & 0.172 & $-0.271^{* *}$ & -0.136 & $-0.253^{* *}$ & -0.060 & -0.102 & -0.181 \\
\hline 4 Financial Difficulty & & & & 1 & $-0.241 *$ & 0.069 & 0.005 & 0.104 & $0.416^{* *}$ & -0.024 & -0.083 & $0.237 *$ \\
\hline 5 Monthly Income & & & & & 1 & $0.192 *$ & -0.176 & -0.095 & -0.135 & 0.156 & -0.068 & -0.166 \\
\hline 6 Marital Status (Married) & & & & & & 1 & $-0.470 * *$ & -0.075 & 0.059 & 0.111 & 0.070 & 0.078 \\
\hline 7 Living Alone & & & & & & & 1 & -0.026 & -0.074 & 0.008 & 0.185 & 0.089 \\
\hline $8 \mathrm{SRH}$ (Poor) & & & & & & & & 1 & $0.240 *$ & 0.078 & 0.005 & 0.084 \\
\hline 9 Depression & & & & & & & & & 1 & 0.113 & -0.016 & $0.316^{* *}$ \\
\hline 10 Obesity & & & & & & & & & & 1 & 0.056 & 0.010 \\
\hline 11 Polypharmacy & & & & & & & & & & & 1 & $0.398^{* *}$ \\
\hline 12 Multimorbidity (Number of CDs) & & & & & & & & & & & & 1 \\
\hline \multicolumn{13}{|l|}{ Women } \\
\hline 1 Gender (Women) & - & - & - & - & - & - & - & - & - & - & - & - \\
\hline 2 Age (Years) & & 1 & -0.098 & $-0.248^{* *}$ & 0.036 & -0.015 & 0.169 * & -0.136 & $-0.261^{* *}$ & -0.103 & $0.214^{* *}$ & 0.046 \\
\hline 3 Educational Attainment & & & 1 & -0.019 & $0.193 * *$ & 0.004 & 0.014 & -0.105 & -0.104 & -0.040 & -0.061 & -0.060 \\
\hline 4 Financial Difficulty & & & & 1 & -0.113 & -0.014 & -0.018 & $0.271^{* *}$ & $0.466^{* *}$ & $0.144^{*}$ & -0.091 & 0.131 \\
\hline 5 Monthly Income & & & & & 1 & $0.282 * *$ & $-0.233 * *$ & -0.061 & -0.134 & 0.094 & -0.113 & -0.141 \\
\hline
\end{tabular}


Table 2. Cont

\begin{tabular}{|c|c|c|c|c|c|c|c|c|c|c|c|c|}
\hline & 1 & 2 & 3 & 4 & 5 & 6 & 7 & 8 & 9 & 10 & 11 & 12 \\
\hline 6 Marital Status (Married) & & & & & & 1 & $-0.300 * *$ & 0.003 & 0.047 & 0.024 & 0.017 & 0.087 \\
\hline 7 Living Alone & & & & & & & 1 & -0.007 & 0.012 & -0.007 & $0.199^{* *}$ & 0.129 \\
\hline 8 SRH (Poor) & & & & & & & & 1 & $0.457^{* *}$ & 0.111 & 0.106 & $0.281^{* *}$ \\
\hline 9 Depression & & & & & & & & & 1 & 0.096 & 0.092 & $0.220^{* *}$ \\
\hline 10 Obesity & & & & & & & & & & 1 & 0.124 & 0.168 * \\
\hline 11 Polypharmacy & & & & & & & & & & & 1 & $0.344^{* *}$ \\
\hline 12 Multimorbidity (Number of CDs) & & & & & & & & & & & & 1 \\
\hline
\end{tabular}

CDs: Chronic Diseases; SRH: Self-Rated Health. ${ }^{*} p<0.05 .{ }^{* *} p<0.001$. (Pearson correlation test). 


\subsection{Multivariable Models}

As Table 3 shows, obesity was associated with polypharmacy in the pooled sample, when multimorbidity was not adjusted in the model. Obesity was no longer associated with polypharmacy in the pooled sample, however, after adjusting for multimorbidity. This suggests that multimorbidity is the mechanism by which obesity is associated with polypharmacy in the pooled sample.

Table 3. Logistic regressions on the associations between gender, obesity, multimorbidity, and polypharmacy in the pooled sample.

\begin{tabular}{|c|c|c|c|c|c|}
\hline Characteristics & OR & Std. Error & \multicolumn{2}{|c|}{$95 \%$ CI } & Sig \\
\hline \multicolumn{6}{|l|}{ Model 1} \\
\hline Gender (Women) & 1.14 & 0.29 & 0.65 & 2.01 & 0.639 \\
\hline Age (Years) & 1.03 & 0.02 & 1.00 & 1.07 & 0.039 \\
\hline Educational Attainment & 0.99 & 0.07 & 0.86 & 1.14 & 0.849 \\
\hline Financial Difficulty & 0.95 & 0.03 & 0.90 & 0.99 & 0.030 \\
\hline Monthly Income & 0.79 & 0.12 & 0.62 & 1.01 & 0.061 \\
\hline Marital Status (Married) & 3.71 & 0.54 & 1.28 & 10.80 & 0.016 \\
\hline Living Alone & 2.67 & 0.31 & 1.46 & 4.87 & 0.001 \\
\hline SRH (Poor) & 1.37 & 0.29 & 0.77 & 2.44 & 0.281 \\
\hline Depression & 1.07 & 0.05 & 0.96 & 1.19 & 0.203 \\
\hline Obesity & 1.73 & 0.28 & 1.00 & 2.99 & 0.051 \\
\hline Constant & 0.21 & 1.73 & & & 0.364 \\
\hline \multicolumn{6}{|l|}{ Model 2} \\
\hline Gender (Women) & 0.89 & 0.31 & 0.49 & 1.62 & 0.692 \\
\hline Age (Years) & 1.03 & 0.02 & 0.99 & 1.06 & 0.129 \\
\hline Educational Attainment & 0.99 & 0.08 & 0.86 & 1.15 & 0.940 \\
\hline Financial Difficulty & 0.93 & 0.03 & 0.88 & 0.98 & 0.007 \\
\hline Monthly Income & 0.85 & 0.13 & 0.66 & 1.10 & 0.212 \\
\hline Marital Status (Married) & 2.72 & 0.60 & 0.85 & 8.78 & 0.093 \\
\hline Living Alone & 2.41 & 0.33 & 1.26 & 4.61 & 0.008 \\
\hline SRH (Poor) & 1.22 & 0.31 & 0.66 & 2.25 & 0.531 \\
\hline Depression & 1.02 & 0.06 & 0.91 & 1.13 & 0.747 \\
\hline Obesity & 1.48 & 0.30 & 0.83 & 2.64 & 0.188 \\
\hline Multimorbidity & 1.67 & 0.10 & 1.38 & 2.02 & 0.000 \\
\hline Constant & 0.07 & 1.85 & & & 0.158 \\
\hline
\end{tabular}

CDs: Chronic Diseases; SRH: Self-Rated Health. Model 1: Obesity only. Model 2: Obesity and multimorbidity.

\subsection{Multivariable Models}

As Table 4 demonstrates, gender differences were found in the association between obesity and polypharmacy. The association between obesity and polypharmacy was significant for older AA women but not older AA men. For older AA women, obesity was associated with polypharmacy, when multimorbidity was not controlled in the model. For AA women, obesity was no longer associated with polypharmacy after controlling for multimorbidity. This suggests that multimorbidity is the mechanism by which obesity is associated with polypharmacy for older AA women (Table 4). 
Table 4. Logistic regressions on the associations between obesity, multimorbidity, and polypharmacy in older AA men and older AA women.

\begin{tabular}{|c|c|c|c|c|c|c|c|c|c|c|}
\hline \multirow{2}{*}{ Characteristics } & OR & Std. Error & \multicolumn{2}{|c|}{$95 \%$ CI } & Sig & OR & Std. Erro & \multicolumn{2}{|c|}{$95 \% \mathrm{CI}$} & Sig \\
\hline & \multicolumn{5}{|c|}{ Men } & \multicolumn{5}{|c|}{ Women } \\
\hline \multicolumn{11}{|l|}{ Model 3} \\
\hline Age (Years) & 0.98 & 0.03 & 0.93 & 1.04 & 0.529 & 1.06 & 0.02 & 1.02 & 1.11 & 0.005 \\
\hline Educational Attainment & 0.90 & 0.12 & 0.71 & 1.13 & 0.349 & 1.02 & 0.10 & 0.85 & 1.24 & 0.808 \\
\hline Financial Difficulty & 0.94 & 0.04 & 0.87 & 1.02 & 0.131 & 0.93 & 0.04 & 0.87 & 1.00 & 0.039 \\
\hline Monthly Income & 0.88 & 0.17 & 0.63 & 1.22 & 0.440 & 0.73 & 0.19 & 0.51 & 1.06 & 0.098 \\
\hline Marital Status (Married) & 4.22 & 0.75 & 0.98 & 18.20 & 0.054 & 3.19 & 0.87 & 0.58 & 17.72 & 0.184 \\
\hline Living Alone & 3.12 & 0.51 & 1.16 & 8.40 & 0.024 & 2.29 & 0.40 & 1.05 & 5.01 & 0.038 \\
\hline SRH (Poor) & 0.99 & 0.45 & 0.41 & 2.37 & 0.975 & 1.51 & 0.41 & 0.67 & 3.37 & 0.317 \\
\hline Depression & 1.01 & 0.08 & 0.86 & 1.19 & 0.879 & 1.14 & 0.08 & 0.98 & 1.32 & 0.086 \\
\hline Obesity & 1.12 & 0.48 & 0.44 & 2.86 & 0.815 & 2.07 & 0.36 & 1.03 & 4.17 & 0.042 \\
\hline Constant & 27.73 & 3.30 & - & - & 0.314 & 0.03 & 2.15 & - & - & 0.109 \\
\hline \multicolumn{11}{|l|}{ Model 4} \\
\hline Age (Years) & 0.96 & 0.04 & 0.90 & 1.03 & 0.248 & 1.06 & 0.02 & 1.01 & 1.11 & 0.010 \\
\hline Educational Attainment & 0.90 & 0.12 & 0.71 & 1.14 & 0.361 & 1.02 & 0.10 & 0.84 & 1.25 & 0.837 \\
\hline Financial Difficulty & 0.91 & 0.05 & 0.83 & 0.99 & 0.026 & 0.92 & 0.04 & 0.86 & 0.99 & 0.030 \\
\hline Monthly Income & 0.92 & 0.19 & 0.63 & 1.33 & 0.643 & 0.82 & 0.20 & 0.56 & 1.19 & 0.293 \\
\hline Marital Status (Married) & 4.01 & 0.88 & 0.72 & 22.42 & 0.114 & 1.91 & 0.92 & 0.32 & 11.57 & 0.481 \\
\hline Living Alone & 2.99 & 0.59 & 0.94 & 9.57 & 0.065 & 2.00 & 0.42 & 0.88 & 4.56 & 0.099 \\
\hline SRH (Poor) & 0.95 & 0.50 & 0.36 & 2.54 & 0.919 & 1.19 & 0.44 & 0.51 & 2.80 & 0.693 \\
\hline Depression & 0.91 & 0.09 & 0.77 & 1.09 & 0.326 & 1.11 & 0.08 & 0.95 & 1.29 & 0.179 \\
\hline Obesity & 0.99 & 0.53 & 0.35 & 2.81 & 0.986 & 1.68 & 0.38 & 0.80 & 3.52 & 0.170 \\
\hline Multimorbidity & 2.03 & 0.18 & 1.43 & 2.89 & 0.000 & 1.56 & 0.12 & 1.22 & 1.99 & 0.000 \\
\hline Constant & 21.98 & 3.64 & - & - & 0.396 & 0.01 & 2.32 & - & - & 0.035 \\
\hline
\end{tabular}

CDs: Chronic Diseases; SRH: Self-Rated Health. Model 3: Obesity only. Model 4: Obesity and multimorbidity.

\section{Discussion}

This study revealed three findings: first, obesity was associated with polypharmacy in AA older adults, above and beyond confounders. Second, the association between obesity and polypharmacy was moderated by gender. Obesity is associated with polypharmacy in older AA women but not in older AA men. Third, the association between obesity and polypharmacy was mediated by multimorbidity (number of CDs).

AA older adults with obesity, particularly women, were more likely to have polypharmacy. Previous research has shown that AA older adults with polypharmacy also report multimorbidity, worse SRH, in addition to depression and psychological distress [25]. In a study of AA adults older than 18 years old, polypharmacy increased the risk of mental distress. Furthermore, in that study, the association between polypharmacy and psychological distress was net of gender and all confounders such as SES and multimorbidity [47]. Other studies have shown that polypharmacy is associated with depression and poor SRH [47]. The current finding adds to the literature and suggests that polypharmacy is also associated with obesity, an association which is due to multimorbidity. Additionally, this information adds to the literature that exists on the link between polypharmacy, depression, distress, and SRH $[25,47]$.

In the current study, gender was a moderator of the association between obesity and polypharmacy. In a recent study, gender changed the association between polypharmacy and SRH [47]. More specifically, poor SRH was indicative of higher odds of polypharmacy in older AA women but not older AA men. Gender differences in correlates of obesity in AAs is well-known and obesity is differently associated with SES, depression, and other factors in male and female AAs across age groups, compared to White people [62-67]. 
Gender impacts both prevalence and correlates of obesity and polypharmacy. Compared to men, women are at higher risk of polypharmacy [42,43]. Even with a lower risk of fatal chronic medical conditions, women are more likely than men to feel worse health [63]. Although some studies have failed to show any gender differences in polypharmacy [64], most of previous studies have documented a higher prevalence of polypharmacy in women than men [42-44]. Women may also be at a higher risk of potentially inappropriate medication use $[14,42,43]$. Due to gendered socialization [65], women are more likely than men to seek help for and communicate about their symptoms. This likely increases the chance of having multiple comorbid medical conditions [66]. At each level of multiple chronic medical conditions, women are more likely than men to seek professional care [65]. Women are more likely to be aware of their health problems and symptoms [63], they have more effective communication skills to share their symptoms with their health care providers. Therefore, there is a tendency for women to have an increased likelihood to be diagnosed with multiple chronic conditions. For some men, masculine ideologies operate as a barrier against seeking healthcare for their health problems, so they are less likely to be diagnosed with chronic disease [68-73]. As a result, men do not effectively share their symptoms with their health care providers [71], which causes a substantial delay in how and when they are diagnosed with a disease [72]. As a result, gender differences emerge in polypharmacy [42]. These processes have implications for emerging gender differences in correlates of polypharmacy in men and women.

The results of this study are not generalizable to the US population because the sample is not a representative sample. The current sample is composed of economically disadvantaged residents that live in poor urban areas. This is important given the protective effect of high SES against polypharmacy $[14,74-76]$ and obesity $[27-29,77,78]$. It is well known that that SES shapes the risk of polypharmacy in AA men and women [14,74-76]. This is further corroborated by the fact that underserved AA older adults experience high levels of financial difficulty, experience struggles accessing the health care system, and have high numbers of chronic diseases.

Polypharmacy, multimorbidity, poor health, and obesity are common and interrelated issues among AA older men and women [79-83]. As all of these conditions are risk factors for morbidity and mortality [84-89], these factors should be addressed jointly. Health promotion programs that address AA older adults in underserved communities should consider the link between obesity and polypharmacy. More specifically, programs and interventions that wish to promote health toward AA older adults in underserved communities should address polypharmacy, multimorbidity, and obesity as common elements of morbidity and mortality of AA older adults. Studies that address medication challenges of the AA community should also not discount or overlook obesity given the close link between obesity, multimorbidity, and polypharmacy.

The link between polypharmacy and BMI may be because of multimorbidity. Future research should address if prevention of obesity will be an effective way to reduce inappropriate polypharmacy for AA older adults $[84,86]$. We are not aware of many evidence-based interventions that are available to reduce risk of obesity or polypharmacy among AA older adults [90,91]. As shown in existing systematic reviews, the effect size of existing interventions that address inappropriate polypharmacy is small [92]. We should develop, implement, and evaluate new interventions that reduce unnecessary polypharmacy and associated morbidity for AA older adults $[93,94]$.

Our models 1 to 3 showed that 'living alone' had a large OR which was statistically significant. Thus, AA older adults living alone are far more likely to use polypharmacy than their counterparts who are not living alone. The mechanism of this finding is not known, and necessitates additional research. Literature has connected social isolation and lack of social support to a wide range of health problems such as depression, chronic disease, and poor self-rated health [95-99]. This finding is important because social isolation is common among AA older adults [96,99].

The results shown by this study may inform public health programs as well as clinical practice to promote the health and well-being of economically disadvantaged AA older adults in urban communities. We argue that the health promotion of AA older adults should address polypharmacy. 
Knowing that gender alters the correlates of polypharmacy, interventions that wish to address medication related challenges of AA older adults may benefit from the gender of the participant. Tailoring such programs to the gender of the participant may help with enhancing the efficacy of such interventions. Future research is needed to understand how addressing medication-related challenges can improve the health and wellbeing of AA older adults in underserved communities.

\section{Limitations}

Our study has a few limitations. As a cross-sectional design, we cannot make any causal inferences. This study only measured the quantity rather than the classification and indication of medications taken. Without knowing such information regarding participants' medications, it is impossible to know the true percentage of participants that are receiving inappropriate polypharmacy. Future work should also measure drug-drug, drug-disease, and drug-consumption interactions in the population. In addition, we did not verify the self-reported multimorbidity using other sources such as medical claims, medical charts, or pharmacy data. Some potentially important confounders were not included. For example, we did not measure psychiatric problems or somatization. In addition, all our variables were measured at an individual level. We also did not collect data on disability, activities of daily living (ADLs), cognition, and frailty. The sample was not random but a convenient sample of AA older adults in South Los Angeles [25,36,47-49,67]. As a such, replication studies are needed using random samples that generate generalizable findings. In addition, most of our participants were AA women which is another reason our findings are not generalizable to the US AA population. This study only included AA older adults. Future comparative studies regarding various ethnic groups and their corresponding levels of obesity and polypharmacy are still needed. Theoretically, the strength of the link between obesity and polypharmacy may change across population subgroups, and obesity may be a stronger risk factor for polypharmacy in some versus other ethnic groups. Lack of information on the type of medications is a major limitation to this study. As such, drug-drug interactions, and the extent to which polypharmacy was inappropriate could not be evaluated. Given these limitations, the results of our study results are preliminary, however, they still may contribute to improvement of the health of economically challenged older AAs. The result contributes to how obesity may increase risk of polypharmacy among AA older adults.

\section{Conclusions}

In summary, among AA older adults, particularly for women, obesity is associated with polypharmacy, and this association is mainly due to higher risk of multimorbidity in obese people. Given the overlaps between obesity, multimorbidity, and polypharmacy interventions that address health of obese older AA women may include screening for inappropriate polypharmacy.

Author Contributions: S.A. prepared the first draft of the paper. M.B. designed the study, conducted the study, collected the data, and revised the manuscript. C.W. contributed to the revision. All authors approved the final draft.

Funding: This study was supported by the Center for Medicare and Medicaid Services (CMS) Grant 1H0CMS331621 to Charles R. Drew University of Medicine and Science (PI: M. Bazargan). Additionally, Dr. Bazargan is supported by the NIH under Award \# “54MD008149" and \# R25 MD007610 (PI: M. Bazargan), 2U54MD007598 (PI: J. Vadgama), and U54 TR001627 (PIs: S. Dubinett and R. Jenders). Shervin Assari is partly supported by the CMS grant 1H0CMS331621 (PI: M. Bazargan), National Institute on Minority Health and Health Disparities (NIMHD) grant U54 MD007598 (PI = M. Bazargan), and the National Cancer Institute (NCI) grant CA201415-02 (Co-PI = R. Mistry).

Conflicts of Interest: The authors declare no conflict of interest. 


\section{References}

1. Mortazavi, S.S.; Shati, M.; Keshtkar, A.; Malakouti, S.K.; Bazargan, M.; Assari, S. Defining polypharmacy in the elderly: A systematic review protocol. BMJ Open 2016, 6, e010989. [CrossRef]

2. Guthrie, B.; Makubate, B.; Hernandez-Santiago, V.; Dreischulte, T. The rising tide of polypharmacy and drug-drug interactions: Population database analysis 1995-2010. BMC Med. 2015, 13. [CrossRef] [PubMed]

3. Ziere, G.; Dieleman, J.P.; Hofman, A.; Pols, H.A.P.; van der Cammen, T.J.M.; Stricker, B.H.C. Polypharmacy and falls in the middle age and elderly population. Br. J. Clin. Pharmacol. 2006, 61, 218-223. [CrossRef]

4. Flaherty, J.H.; Perry, H.M.; Lynchard, G.S.; Morley, J.E. Polypharmacy and hospitalization among older home care patients. J. Gerontol. A Biol. Sci. Med. Sci. 2000, 55, M554-M559. [CrossRef]

5. Lau, D.T.; Mercaldo, N.D.; Harris, A.T.; Trittschuh, E.; Shega, J.; Weintraub, S. Polypharmacy and potentially inappropriate medication use among community-dwelling elders with dementia. Alzheimer Dis. Assoc. Disord. 2010, 24, 56. [CrossRef] [PubMed]

6. Taylor, L.K.; Kawasumi, Y.; Bartlett, G.; Tamblyn, R. Inappropriate prescribing practices: The challenge and opportunity for patient safety. Healthc. Q. 2005, 8, 81-85. [CrossRef]

7. Sapkota, S.; Pudasaini, N.; Singh, C.; Sagar, G.C. Drug prescribing pattern and prescription error in elderly: A retrospective study of inpatient record. Asian J. Pharm. Clin. Res. 2011, 4, 129-132.

8. Majdan, M.; Mauritz, W. Unintentional fall-related mortality in the elderly: Comparing patterns in two countries with different demographic structure. BMJ Open 2015, 5, e008672. [CrossRef] [PubMed]

9. Wimmer, B.C.; Bell, J.S.; Fastbom, J.; Wiese, M.D.; Johnell, K. Medication regimen complexity and number of medications as factors associated with unplanned hospitalizations in older people: A population-based cohort study. J. Gerontol. A Biol. Sci. Med. Sci. 2016, 71, 831-837. [CrossRef]

10. Wimmer, B.C.; Bell, J.S.; Fastbom, J.; Wiese, M.D.; Johnell, K. Medication regimen complexity and polypharmacy as factors associated with all-cause mortality in older people. Ann. Pharmacother. 2016, 50, 89-95. [CrossRef]

11. Maher, R.L.; Hanlon, J.; Hajjar, E.R. Clinical consequences of polypharmacy in elderly. Expert Opin. Drug Saf. 2014, 13, 57-65. [CrossRef] [PubMed]

12. Salazar, J.A.; Poon, I.; Nair, M. Clinical consequences of polypharmacy in elderly: Expect the unexpected, think the unthinkable. Expert Opin. Drug Saf. 2007, 6, 695-704. [CrossRef]

13. Parameswaran Nair, N.; Chalmers, L.; Peterson, G.M.; Bereznicki, B.J.; Castelino, R.L.; Bereznicki, L.R. Hospitalization in older patients due to adverse drug reactions -the need for a prediction tool. Clin. Interv. Aging 2016, 11, 497-505. [CrossRef] [PubMed]

14. Byles, J.E.; Heinze, R.; Nair, B.K.; Parkinson, L. Medication use among older Australian veterans and war widows. Intern. Med. J. 2003, 33, 388-392. [CrossRef] [PubMed]

15. Craig, R.; Mindell, J. Health Survey for England 2013; The Health and Social Care Information Centre: London, UK, 2014.

16. Viktil, K.K.; Blix, H.S.; Moger, T.A.; Reikvam, A. Polypharmacy as commonly defined is an indicator of limited value in the assessment of drug-related problems. Br. J. Clin. Pharmacol. 2007, 63, 187-195. [CrossRef] [PubMed]

17. Rossi, M.I.; Young, A.; Maher, R.; Rodriguez, K.L.; Appelt, C.J.; Perera, S.; Hajjar, E.R.; Hanlon, J.T. Polypharmacy and health beliefs in older outpatients. Am. J. Geriatr. Pharmacother. 2007, 5, 317-323. [CrossRef] [PubMed]

18. Hajjar, E.R.; Hanlon, J.T.; Sloane, R.J.; Lindblad, C.I.; Pieper, C.F.; Ruby, C.M.; Branch, L.C.; Schmader, K.E. Unnecessary drug use in frail older people at hospital discharge. J. Am. Geriatr. Soc. 2005, 53, 1518-1523. [CrossRef] [PubMed]

19. Chan, M.; Nicklason, F.; Vial, J.H. Adverse drug events as a cause of hospital admission in the elderly. Intern. Med. J. 2001, 31, 199-205. [CrossRef]

20. Hovstadius, B.; Petersson, G. Factors leading to excessive polypharmacy. Clin. Geriatr. Med. 2012, 28, 159-172. [CrossRef]

21. Aparasu, R.R.; Mort, J.R.; Brandt, H. Polypharmacy trends in office visits by the elderly in the United States, 1990 and 2000. Res. Soc. Adm. Pharm. 2005, 1, 446-459. [CrossRef]

22. Kim, H.-A.; Shin, J.-Y.; Kim, M.-H.; Park, B.-J. Prevalence and predictors of polypharmacy among Korean elderly. PLoS ONE 2014, 9, e98043. [CrossRef] [PubMed] 
23. O’Dwyer, M.; Peklar, J.; McCallion, P.; McCarron, M.; Henman, M.C. Factors associated with polypharmacy and excessive polypharmacy in older people with intellectual disability differ from the general population: A cross-sectional observational nationwide study. BMJ Open 2016, 6, e010505. [CrossRef] [PubMed]

24. Bazargan, M.; Smith, J.; Movassaghi, M.; Martins, D.; Yazdanshenas, H.; Salehe Mortazavi, S.; Orum, G. Polypharmacy among underserved older African American adults. J. Aging Res. 2017. [CrossRef] [PubMed]

25. Assari, S.; Bazargan, M. Polypharmacy and Psychological Distress May Be Associated in African American Adults. Pharmacy 2019, 7, E14. [CrossRef] [PubMed]

26. Hankerson, S.H.; Fenton, M.C.; Geier, T.J.; Keyes, K.M.; Weissman, M.M.; Hasin, D.S. Racial differences in symptoms, comorbidity, and treatment for major depressive disorder among Black and white adults. J. Natl. Med. Assoc. 2011, 103, 576-584. [CrossRef]

27. Moghani Lankarani, M.; Assari, S. Association between Actual and Perceived Obesity Weaker among Black than White Children. Behav. Sci. 2018, 8, 48. [CrossRef] [PubMed]

28. Assari, S. High Income Protects Whites but Not African Americans against Risk of Depression. Healthcare 2018, 6, 37. [CrossRef] [PubMed]

29. Assari, S.; Thomas, A.; Caldwell, C.H.; Mincy, R.B. Blacks' Diminished Health Return of Family Structure and Socioeconomic Status; 15 Years of Follow-up of a National Urban Sample of Youth. J. Urban Health. 2018, 95, 21-35. [CrossRef] [PubMed]

30. Cornwell, E.Y.; Waite, L.J. Social disconnectedness, perceived isolation, and health among older adults. J. Health Soc. Behav. 2009, 50, 31-48. [CrossRef]

31. Cornwell, E.Y.; Waite, L.J. Measuring social isolation among older adults using multiple indicators from the NSHAP study. J. Gerontol. B Psychol. Sci. Soc. Sci. 2009, 64, 38-46. [CrossRef]

32. Payne, R.A.; Avery, A.J.; Duerden, M.; Saunders, C.L.; Simpson, C.R.; Abel, G.A. Prevalence of polypharmacy in a Scottish primary care population. Eur. J. Clin. Pharmacol. 2014, 70, 575-581. [CrossRef] [PubMed]

33. Centers for Disease Control and Prevention and The Merck Institute of Aging \& Health. The State of Aging and Health in America. 2004. Available online: https://www.cdc.gov/aging/pdf/state_of_aging_and_health_ in_america_2004.pdf (accessed on 14 June 2016).

34. Veehof, L.J.G.; Stewart, R.E.; HBlackijer-Ruskamp, F.M.; Meyboom-de Jong, B. The development of polyphamacy. A longitudinal study. Fam. Pract. 2000, 17, 261-267. [CrossRef] [PubMed]

35. Barnett, K.; Mercer, S.W.; Norbury, M.; Watt, G.; Wyke, S.; Guthrie, B. Epidemiology of multimorbidity and implications for health care, research, and medical education: A cross-sectional study. Lancet 2012. [CrossRef]

36. Bazargan, M.; Smith, J.L.; King, E.O. Potentially inappropriate medication use among hypertensive older African-American adults. BMC Geriatr. 2018, 18, 238. [CrossRef] [PubMed]

37. Bazargan, M.; Smith, J.; Yazdanshenas, H.; Movassaghi, M.; Martins, D.; Orum, G. Non-adherence to medication regimens among older African-American adults. BMC Geriatr. 2017, 17, 163. [CrossRef] [PubMed]

38. Wang, J.; Zuckerman, I.H.; Miller, N.A.; Shaya, F.T.; Noel, J.M.; Mullins, C.D. Utilizing new prescription drugs: Disparities among non-Hispanic whites, non-Hispanic Blacks, and Hispanic whites. Health Serv. Res. 2007, 42, 1499-1519. [CrossRef] [PubMed]

39. Wang, J.; Noel, J.M.; Zuckerman, I.H.; Miller, N.A.; Shaya, F.T.; Mullins, C.D. Disparities in access to essential new prescription drugs between non-Hispanic whites, non-Hispanic Blacks, and Hispanic whites. Med. Care Res. Rev. 2006, 63, 742-763. [CrossRef]

40. Venturini, C.D.; Engroff, P.; Ely, L.S.; Zago, L.F.; Schroeter, G.; Gomes, I.; De Carli, G.A.; Morrone, F.B. Gender differences, polypharmacy, and potential pharmacological interactions in the elderly. Clinics 2011, 66, 1867-1872.

41. Assari, S. Gender differences in the predictive role of self-rated health on short-term risk of mortality among older adults. SAGE Open Med. 2016, 4. [CrossRef]

42. Johnell, K.; Weitoft, G.R.; Fastbom, J. Sex differences in inappropriate drug use: A register-based study of over 600,000 older people. Ann. Pharmacother. 2009, 43, 1233-1238. [CrossRef]

43. Johnell, K.; Fastbom, J.; Rosén, M.; Leimanis, A. Inappropriate drug use in the elderly: A nationwide register-based study. Ann. Pharmacother. 2007, 41, 1243-1248. [CrossRef] [PubMed] 
44. Turner, J.P.; Jamsen, K.M.; Shakib, S.; Singhal, N.; Prowse, R.; Bell, J.S. Polypharmacy cut-points in older people with cancer: How many medications are too many? Support Care Cancer 2016, 24, 1831-1840. [CrossRef] [PubMed]

45. Scottish Government Model of Care Polypharmacy Working Group. Polypharmacy Guidance, 2nd ed. 2015. Available online: http://www.sehd.scot.nhs.uk/publications/DC20150415polypharmacy.pdf (accessed on 3 May 2019).

46. Scott, I.A.; Hilmer, S.N.; Reeve, E.; Potter, K.; Le Couteur, D.; Rigby, D.; Gnjidic, D.; Del Mar, C.B.; Roughead, E.E.; Page, A.; et al. Reducing inappropriate polypharmacy: The process of deprescribing. JAMA Intern. Med. 2015, 175, 827-834. [CrossRef] [PubMed]

47. Bazargan, M.; Smith, J.; Saqib, M.; Helmi, H.; Assari, S. Associations between Polypharmacy, Self-Rated Health, and Depression in African American Older Adults; Mediators and Moderators. Int. J. Environ. Res. Public Health. 2019, 16, 1574. [CrossRef] [PubMed]

48. Assari, S.; Smith, J.L.; Zimmerman, M.A.; Bazargan, M. Cigarette Smoking among Economically Disadvantaged African-American Older Adults in South Los Angeles: Gender Differences. Int. J. Environ. Res. Public Health 2019, 16, 1208. [CrossRef] [PubMed]

49. Bazargan, M.; Smith, J.L.; Cobb, S.; Barkley, L.; Wisseh, C.; Ngula, E.; Thomas, R.J.; Assari, S. Emergency Department Utilization among Underserved African American Older Adults in South Los Angeles. Int. J. Environ. Res. Public Health 2019, 16, 1175. [CrossRef] [PubMed]

50. Almeida, O.P.; Almeida, S.A. Reliability of the Brazilian version of the ++ abbreviated form of Geriatric Depression Scale (GDS) short form. Arq. Neuropsiquiatr. 1999, 57, 421-426. [CrossRef] [PubMed]

51. Bae, J.N.; Cho, M.J. Development of the Korean version of the Geriatric Depression Scale and its short form among elderly psychiatric patients. J. Psychosom. Res. 2004, 57, 297-305. [CrossRef] [PubMed]

52. Chiang, K.S.; Green, K.E.; Cox, E.O. Rasch analysis of the Geriatric Depression Scale-Short Form. Gerontologist 2009, 49, 262-275. [CrossRef]

53. Durmaz, B.; Soysal, P.; Ellidokuz, H.; Isik, A.T. Validity and reliability of geriatric depression scale-15 (short form) in Turkish older adults. North Clin. İstanbul 2018, 5, 216-220. [CrossRef]

54. Ferraro, F.R.; Chelminski, I. Preliminary normative data on the Geriatric Depression Scale-Short Form (GDS-SF) in a young adult sample. J. Clin. Psychol. 1996, 52, 443-447. [CrossRef]

55. Bora, J.K.; Saikia, N. Gender Differentials in Self-Rated Health and Self-Reported Disability among Adults in India. PLoS ONE 2015, 10, e0141953. [CrossRef]

56. Schnittker, J.; Bacak, V. The increasing predictive validity of self-rated health. PLoS ONE 2014, 9, e84933. [CrossRef] [PubMed]

57. Idler, E.L.; Benyamini, Y. Self-rated health and mortality: A review of twenty-seven community studies. J. Health Soc. Behav. 1997, 38, 21-37. [CrossRef]

58. Thong, M.S.; Kaptein, A.A.; Benyamini, Y.; Krediet, R.T.; Boeschoten, E.W.; Dekker, F.W.; Netherlands Cooperative Study on the Adequacy of Dialysis (NECOSAD) Study Group. Association between a self-rated health question and mortality in young and old dialysis patients: A cohort study. Am. J. Kidney Dis. 2008, 52, 111-117. [CrossRef] [PubMed]

59. Fowles, J.B.; Fowler, E.J.; Craft, C. Validation of claims diagnoses and self-reported conditions compared with medical records for selected chronic diseases. J. Ambul. Care Manag. 1998, 21, 24-34. [CrossRef]

60. HeliovBlackra, M.; AromBlack, A.; Klaukka, T.; Knekt, P.; JoukamBlack, M.; ImpivBlackra, O. Reliability and validity of interview data on chronic diseases. The Mini-Finland Health Survey. J. Clin. Epidemiol. 1993, 46, 181-191.

61. Martin, L.M.; Leff, M.; Calonge, N.; Garrett, C.; Nelson, D.E. Validation of self-reported chronic conditions and health services in a managed care population. Am. J. Prev. Med. 2000, 18, 215-218. [CrossRef]

62. Al-Hashar, A.; Al Sinawi, H.; Al Mahrizi, A.; Al-Hatrushi, M. Prevalence and Covariates of Polypharmacy in Elderly Patients on Discharge from a Tertiary Care Hospital in Oman. Oman Med. J. 2016, 31, 421-425. [CrossRef]

63. Gijsber van Wijk, C.M.T.; Kolk, A.M.; van den Bosch, W.J.H.M.; van den Hoogen, H.J. Male and female morbidity in general practice: The nature of sex differences. Soc. Sci. Med. 1992, 35, 665-678. [CrossRef]

64. Regitz-Zagrosek, V. Sex and gender differences in health. Science \& Society Series on Sex and Science. EMBO Rep. 2012, 13, 596-603. [CrossRef] [PubMed] 
65. Bertakis, K.D.; Azari, R.; Helms, L.J.; Callahan, E.J.; Robbins, J.A. Gender differences in the utilization of health care services. J. Fam. Pract. 2000, 49, 147-152. [PubMed]

66. Vlahiotis, A.; Sedjo, R.; Cox, E.R.; Burroughs, T.E.; Rauchway, A.; Lich, R. Gender differences in self-reported symptom awareness and perceived ability to manage therapy with disease-modifying medication among commercially insured multiple sclerosis patients. J. Manag. Care Pharm. 2010, 16, 206-216. [CrossRef] [PubMed]

67. Cobb, S.; Assari, S. Self-Rated Health in African American Men and Women; Evidence for Sponge Hypothesis. 2019; (under review).

68. Galdas, P.M.; Cheater, F.; Marshall, P. Men and health help-seeking behaviour: Literature review. J. Adv. Nurs. 2005, 49, 616-623. [CrossRef]

69. Hammond, W.P.; Matthews, D.; Mohottige, D.; Agyemang, A.; Corbie-Smith, G. Masculinity, medical mistrust, and preventive health services delays among community-dwelling African-American men. J. Gen. Intern. Med. 2010, 25, 1300-1308. [CrossRef] [PubMed]

70. Addis, M.E.; Mahalik, J.R. Men, masculinity, and the contexts of help seeking. Am. Psychol. 2003, 58, 5. [CrossRef] [PubMed]

71. Murtagh, K.N.; Hubert, H.B. Gender differences in physical disability among an elderly cohort. Am. J. Public Health 2004, 94, 1406-1411. [CrossRef]

72. Courtenay, W.H. Constructions of masculinity and their influence on men's well-being: A theory of gender and health. Soc. Sci. Med. 2000, 50, 1385-1401. [CrossRef]

73. Braybrook, D.E.; Witty, K.R.; Robertson, S. Men and lung cancer: A review of the barriers and facilitators to male engagement in symptom reporting and screening. J. Mens Health. 2011, 8, 93-99. [CrossRef]

74. Haider, S.I.; Johnell, K.; Thorslund, M.; Fastbom, J. Analysis of the association between polypharmacy and socioeconomic position among elderly aged $>$ or $=77$ years in Sweden. Clin. Ther. 2008, 30, 419-427. [CrossRef]

75. Haider, S.I.; Johnell, K.; Weitoft, G.R.; Thorslund, M.; Fastbom, J. The influence of educational level on polypharmacy and inappropriate drug use: A register-based study of more than 600,000 older people. J. Am. Geriatr. Soc. 2009, 57, 62-69. [CrossRef] [PubMed]

76. Assari, S. Social Determinants of Depression: The Intersections of Race, Gender, and Socioeconomic Status. Brain Sci. 2017, 7, E156. [CrossRef] [PubMed]

77. Assari, S. Baseline Body Mass Predicts Average Depressive Symptoms over the Next Two Decades for White but Not Black Older Adults. Geriatrics 2019, 4, 14. [CrossRef] [PubMed]

78. Assari, S. Family Income Reduces Risk of Obesity for White but Not Black Children. Children 2018, 5, 73. [CrossRef] [PubMed]

79. Pierce, M.B.; Silverwood, R.J.; Nitsch, D.; Adams, J.E.; Stephen, A.M.; Nip, W.; Macfarlane, P.; Wong, A.; Richards, M.; Hardy, R.; et al. Clinical disorders in a post war British cohort reaching retirement: Evidence from the first National Birth Cohort study. PLoS ONE 2012, 7, e44857. [CrossRef]

80. Kuh, D.; Wong, A.; Shah, I.; Moore, A.; Popham, M.; Curran, P.; Davis, D.; Sharma, N.; Richards, M.; Stafford, M.; et al. The MRC National Survey of health and development reaches age 70: Maintaining participation at older ages in a birth cohort study. Eur. J. Epidemiol. 2016, 31, 1135-1147. [CrossRef] [PubMed]

81. American Geriatrics Society 2015 Beers Criteria Update Expert Panel. American Geriatrics Society 2015 Updated Beers Criteria for Potentially Inappropriate Medication Use in Older Adults. J. Am. Geriatr. Soc. 2015, 63, 2227-2246. [CrossRef]

82. Assari, S.; Helmi, H.; Bazargan, M. Polypharmacy in African American Adults: A National Epidemiological Study. Pharmacy 2019, 7, 33. [CrossRef]

83. Bazargan, M.; Yazdanshenas, H.; Gordon, D.; Orum, G. Pain in Community-Dwelling Elderly African Americans. J. Aging Health 2016, 28, 403-425. [CrossRef]

84. Assari, S. Psychosocial Correlates of Body Mass Index in the United States: Intersection of Race, Gender and Age. Iran J. Psychiatry Behav. Sci. 2016, 10, e3458. [CrossRef]

85. Assari, S. Psychiatric disorders differently correlate with physical self-rated health across ethnic groups. J. Pers. Med. 2017, 7, 6. [CrossRef] [PubMed]

86. Hajjar, E.R.; Cafiero, A.C.; Hanlon, J.T. Polypharmacy in elderly patients. Am. J. Geriatr. Pharmacother. 2007, 5, 345-351. [CrossRef] [PubMed] 
87. Steel, Z.; Marnane, C.; Iranpour, C.; Chey, T.; Jackson, J.W.; Patel, V.; Silove, D. The global prevalence of common mental disorders: A systematic review and meta-analysis 1980-2013. Int. J. Epidemiol. 2014, 43, 476-493. [CrossRef] [PubMed]

88. Ferraro, K.F.; Nuriddin, T.A. Psychological distress and mortality: Are women more vulnerable? J. Health Soc. Behav. 2006, 47, 227-241. [CrossRef] [PubMed]

89. Russ, T.C.; Stamatakis, E.; Hamer, M.; Starr, J.M.; Kivimäki, M.; Batty, G.D. Association between psychological distress and mortality: Individual participant pooled analysis of 10 prospective cohort studies. BMJ 2012, 345, e4933. [CrossRef]

90. Farrell, B.; Shamji, S.; Monahan, A.; French Merkley, V. Reducing polypharmacy in the elderly: Cases to help you "rock the boat". Can. Pharm. J. 2013, 146, 243-244. [CrossRef]

91. Cooper, J.A.; Cadogan, C.A.; Patterson, S.M.; Kerse, N.; Bradley, M.C.; Ryan, C.; Hughes, C.M. Interventions to improve the appropriate use of polypharmacy in older people: A Cochrane systematic review. BMJ Open 2015, 5, e009235. [CrossRef]

92. Johansson, T.; Abuzahra, M.E.; Keller, S.; Mann, E.; Faller, B.; Sommerauer, C.; Höck, J.; Löffler, C.; Köchling, A.; Schuler, J.; et al. Impact of strategies to reduce polypharmacy on clinically relevant endpoints: A systematic review and meta-analysis. Br. J. Clin. Pharmacol. 2016. [CrossRef]

93. Hawthorne, A.B.; Rubin, G.; Ghosh, S. Review article: Medication non-adherence in ulcerative colitis-Strategies to improve adherence with mesalazine and other maintenance therapies. Aliment. Pharmacol. Ther. 2008, 27, 1157-1166. [CrossRef]

94. Claxton, A.J.; Cramer, J.; Pierce, C. A systematic review of the associations between dose regimens and medication compliance. Clin. Ther. 2001, 23, 1296-1310. [CrossRef]

95. Liang, Y.; Gong, Y.H.; Wen, X.P.; Guan, C.P.; Li, M.C.; Yin, P.; Wang, Z.Q. Social determinants of health and depression: A preliminary investigation from rural China. PLoS ONE 2012, 7, e30553. [CrossRef] [PubMed]

96. Taylor, R.J.; Chatters, L.M.; Taylor, H.O. Race and Objective Social Isolation: Older African Americans, Black Caribbeans, and Non-Hispanic Whites. J. Gerontol. B Psychol. Sci. Soc. Sci. 2018. [CrossRef]

97. Chatters, L.M.; Taylor, H.O.; Nicklett, E.J.; Taylor, R.J. Correlates of Objective Social Isolation from Family and Friends among Older Adults. Healthcare 2018, 6, 24. [CrossRef] [PubMed]

98. Taylor, H.O.; Taylor, R.J.; Nguyen, A.W.; Chatters, L. Social Isolation, Depression, and Psychological Distress Among Older Adults. J. Aging Health. 2018, 30, 229-246. [CrossRef]

99. Taylor, R.J.; Taylor, H.O.; Chatters, L.M. Social Isolation from Extended Family Members and Friends among African Americans: Findings from a National Survey. J. Fam. Soc. Work 2016, 19, 443-461. [CrossRef] [PubMed]

(C) 2019 by the authors. Licensee MDPI, Basel, Switzerland. This article is an open access article distributed under the terms and conditions of the Creative Commons Attribution (CC BY) license (http://creativecommons.org/licenses/by/4.0/). 